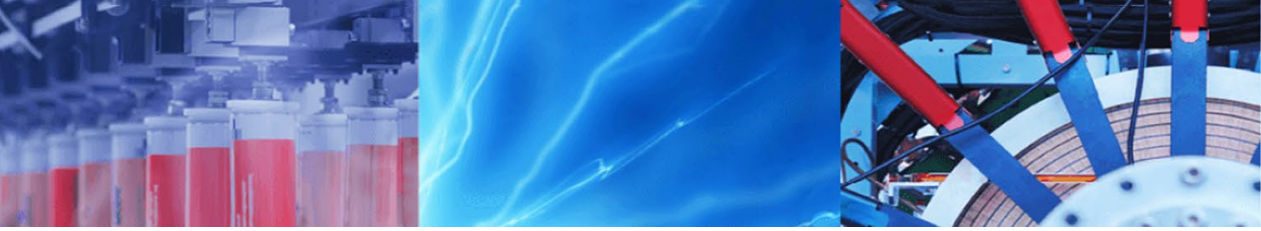

Research Article

\title{
Strong solar flare detection and its impact on ionospheric layers and on coordinates accuracy in the Western Balkans in October 2014
}

\author{
Randa Natras $^{1,2}$ D $\cdot$ Dzana Horozovic ${ }^{1}$ Medzida Mulic ${ }^{2}$
}

(c) Springer Nature Switzerland AG 2018

\begin{abstract}
Activities on the Sun's surface can produce dynamic conditions in the Earth's outer space environment, which can affect the Earth, space-borne and ground-based technologies, including Global Navigation Satellite Systems (GNSS). Delay of GNSS signal can occur during its propagation through the upper Earth's atmosphere-the ionosphere, representing the major limitation in GNSS positioning applications. In this paper, high level of solar activity and intense bursts of radiation from the release of magnetic energy on the Sun, known as solar flares, are studied. The investigation covers the detection of events on the Sun's surface, conditions in near-Earth's space environment, geomagnetic field, ionosphere and GNSS positioning estimates. In October 2014, more than 200 solar flares were detected and about a quarter of total amount belonged to solar flares of $\mathrm{M}$ and $\mathrm{X}$ class. Impact on ionospheric layers is studied: D layer with SuperSID (sudden ionospheric disturbances) monitor and electron density to F2 layer with GNSS-derived total electron content. Used GNSS stations belong to EUREF Permanent Network (EPN) in Bosnia and Herzegovina and Croatia. Precise Point Positioning is performed in the Bernese GNSS Software. Solar radio emissions were high in the second half of the month, when more $\mathrm{M}$ and $\mathrm{X}$ solar flares occurred. Ionospheric electron density was enhanced, reaching its peak during the high level of solar activity and the period of strongest solar flares occurrence, while position estimates show higher deviations from the EPN weekly solution in Up component (at least for two times). Higher-order ionospheric terms remained after applying the L3 ionosphere-free solution, which should be taken into account in precise positioning during increased level of solar activity.
\end{abstract}

Keywords GNSS · lonosphere · Precise point positioning (PPP) - Solar flare · Sudden ionospheric disturbances (SID) Total electron content (TEC)

\section{Introduction}

A solar flare is as a sudden and immense explosion on the Sun, where energy, from the inner region of the Sun, is being released. Solar flares represent one of the most powerful manifestations of the solar activity. They appear on sunspot areas, located on Sun's magnetic regions. The frequency of solar flare occurrences coincides with the 11-year solar cycle, with the maximum occurrence during the solar maximum [1]. Solar flares can be classified, according to the peak flux (in Watt $/ \mathrm{m}^{2}$ ) of X-rays with wavelengths of $100-800^{*} 10^{-12} \mathrm{~m}$, which is given in Table 1 . It has to be noted that within each class, there is a linear scale from 1 to 9; therefore, an X2 solar flare is twice as powerful as an $\mathrm{X} 1$ solar flare, and four times more powerful than an M5 solar flare [2].

These flares can be associated with solar magnetic storms known as coronal mass ejections (CMEs), streams

Authors are thankful to reviewer for his/her valuable comments and suggestions to improve the quality of the manuscript.

\footnotetext{
$\triangle$ Randa Natras, randa.natras1@gmail.com | 'Department of Geodesy and Geoinformation, Vienna University of Technology (TU Wien), Gußhausstraße 27-29, 1040 Vienna, Austria. ${ }^{2}$ Department of Geodesy, Faculty of Civil Engineering, University of Sarajevo, Patriotske lige 30, 71000 Sarajevo, Bosnia and Herzegovina.
} 
Table 1 Classification of solar flares

\begin{tabular}{ll}
\hline Class & Intensity $\left(\right.$ Watt $\left./ \mathrm{m}^{2}\right)$ \\
\hline $\mathrm{X}$ & $10^{-4} \leq I$ \\
$\mathrm{M}$ & $10^{-5} \leq I<10^{-4}$ \\
$\mathrm{C}$ & $10^{-6} \leq I<10^{-5}$ \\
$\mathrm{~B}$ & $10^{-7} \leq I<10^{-6}$ \\
$\mathrm{~A}$ & $I<10^{-7}$ \\
\hline
\end{tabular}

of very fast protons (solar energetic particle events-SEP) and disturbances in the solar wind known as co-rotating interaction regions (CIRs). Consequently, variety of "storms" on Earth can be produced, known as space weather. Space weather can be defined as conditions on the Sun and in the solar wind, magnetosphere, ionosphere and thermosphere that can influence the performance and reliability of space-borne and ground-based technological systems and affect human life and health [3]. If strong enough, it can interfere with short-wave radio communications, Global Navigation Satellite Systems (GNSS) signals and Earth's power grid, among other things.

The level of solar activity and solar cycle is usually presented with sunspot number (SSN) and solar radio flux of Sun's emission at $10.7 \mathrm{~cm}$ wavelength (F10.7 cm). Sunspot number (Wolf number) measures the number of sunspots and groups of sunspots presented on the surface of the Sun [4]. Solar radio emissions from the solar disc at $2800 \mathrm{MHz}$ (10.7 cm wavelength) are recorded routinely since 1947 [5].

Transferred energy from Sun to the Earth can be described with solar wind (SW) velocity. It interacts with Earth's magnetosphere and consequently can induce disturbances in the interplanetary magnetic field (IMF) and the geomagnetic field (GMF) [6]. Geomagnetic activity is usually presented by the index $\mathrm{Kp}$ [7] and its equivalent Ap. Magnetic variations due to globally symmetrical equatorial electrojet are described by the Dst (disturbance storm time) index [8], derived from a network of near-equatorial geomagnetic observatories. Temporary disturbances of the Earth's magnetosphere are known as geomagnetic storms. These processes have effect on the Earth's upper atmosphere, such as ionosphere, which is especially interesting for users of GNSS.

lonosphere is the ionized region of the upper atmosphere, from about $50 \mathrm{~km}$ up to $1,000 \mathrm{~km}$ or more from Earth's surface, containing free electrons and ions produced by solar radiation [9]. Free electrons in the ionosphere are able to affect microwave signal's propagation and introduce signal's delay or advance; especially, vulnerable are single-frequency GNSS users. Using GNSS receivers with more frequencies, ionospheric effects can be measured or corrected using at least two different signal frequencies [10].
Within the ionosphere, several different regions can be distinguished: the $D$ layer (between about $50 \mathrm{~km}$ and $90 \mathrm{~km}$ above the Earth), E layer (between about $90 \mathrm{~km}$ and $150 \mathrm{~km}$ ) and $\mathrm{F}$ layer (above $150 \mathrm{~km}$ ) which splits into $\mathrm{F} 1$ and F2 layers [9]. The source of their ionization during the day is solar radiation (Sun's X-ray and UV light) and cosmic rays during the night. The electron density is the highest in the upper $F$ layer. During the night, the $D$ layer disappears and the E layer becomes weaker. Enhanced $X$-ray fluxes from solar flares can cause sudden increase of ionization in the Earth's ionosphere, up to the lowest $D$ region, known as sudden ionosphere disturbances (SID). The low-frequency (LF) and very low-frequency (VLF) radio waves, emitted from transmitters on the Earth, bounce off the lower ionosphere and provide opportunity to monitor $\mathrm{D}$ region. To study ionization up to higher ionosphere regions (F2 region), total electron content (TEC) derived from two-frequency GNSS observations is suitable. TEC is directly related to the signal propagation delay due to the ionosphere. It represents the total amount of free electrons along the signals' path from satellite to receiver, measured in TEC units (TECU), where 1 TECU $=10^{16}$ electrons $/ \mathrm{m}^{2}[11]$.

Earlier studies of the ionosphere in Bosnia and Herzegovina (B\&H) included investigation of the ionospheric $D$ layer with VLF signals from a SuperSID monitor located in Sarajevo [12] and ionosphere GNSS-derived TEC variability over B\&H during solar maximum and declining phase of solar cycle $24[13,14]$ with studies of impact of space weather and seismic activity $[15,16]$. In addition, the impact of ionosphere's variability on Precise Point Positioning during periods of the strongest geomagnetic storms in solar cycle 24 was studied [17], while the GNSS-based precise ionosphere TEC model for the region of $\mathrm{B} \& \mathrm{H}$ is currently under development [18].

The objective of this research is to analyse the impact of high level of solar activity and the occurrence of solar flares on the near-Earth environment, on the ionosphere and indirectly on GNSS positioning estimates. Solar radiation is primary source of the ionization in ionosphere, which further affects the propagation of GNSS signals from satellite to the receiver and consequently influences GNSS positioning solutions. Research period was selected to be October 2014, due to the high solar activity level characterized with a high number of solar flares, especially the stronger ones ( $\mathrm{M}$ and $\mathrm{X}$ classes). The period of investigation refers to the maximum of solar cycle 24, which reached its peak in April 2014. Investigation includes study of different indices of space weather (SSN, F10.7, SW, Dst, $\mathrm{Kp}$ and $\mathrm{Ap}$ ). GNSS observations of permanent stations in Western Balkan precisely in $\mathrm{B} \& \mathrm{H}$ and Croatia are used in two directions: for estimation of ionospheric TEC to F2 layer and for Precise Point Positioning (PPP). In addition, 
using very low-frequency signals (VLF) from monitor SRJV_ION 0436 located in Sarajevo, sudden ionization in the ionospheric $\mathrm{D}$ layer is measured.

\section{Methodology}

Different data are applied in this study. Indices of solar activity level and data from Geostationary Operational Environmental Satellites (GOES) and SuperSID monitor were used to present solar activities. Indices of solar wind and Earth's magnetic field showed energy transport from the Sun to the Earth and the state in the geomagnetic field. Ground-based GNSS observations of station SRJV (Sarajevo, B\&H), which belongs to the EUREF Permanent Network (EPN), were used to estimate the total electron content (TEC) in the ionosphere and to perform GNSS static and kinematic Precise Point Positioning (PPP). The station is located at the same place as the SuperSID monitor (Department of Geodesy, Faculty of Civil Engineering, University of Sarajevo). For the EPN station SRJV, no observation data were available after the 23rd October. Thus, additionally three EPN stations in Croatia were introduced: DUB2, POZE and ZADA (Fig. 1).
Solar radio flux, sunspot numbers, near-Earth solar wind magnetic field and plasma parameter data were collected from the OMNIWeb interface of Goddard Space Flight Center, Space Physics Data Facility of NASA [19]. Hourly Dst indices were computed at the World Data Center for Geomagnetism, operated by the Data Analysis Center for Geomagnetism and Space Magnetism at Kyoto University, Japan [20]. Geomagnetic activity indices Kp (3-hr) were estimated in German Research Center for Geosciences [21] and NOAA/NWS Space Weather Prediction Center [22]. Dual-frequency GNSS measurements of station SRJV were downloaded from the EUREF database [23].

Space weather monitors track changes in VLF signals, transmitted from stations located all over the world, when they bounce off the ionospheric D layer [24]. The signal strength depends on the Sun's effect on the ionosphere. The software SuperSID, developed at the University in Stanford, was used to collect the data of sudden ionization in the ionospheric D layer due to solar flares. The space weather monitor SRJV_ION 0436, located in Sarajevo, is permanently collecting data from three VLF transmitters (Table 2) used in this research. The complete list of currently active VLF transmitters can be found on the website of the Sudden lonospheric Disturbances Monitoring Station A118 [25].

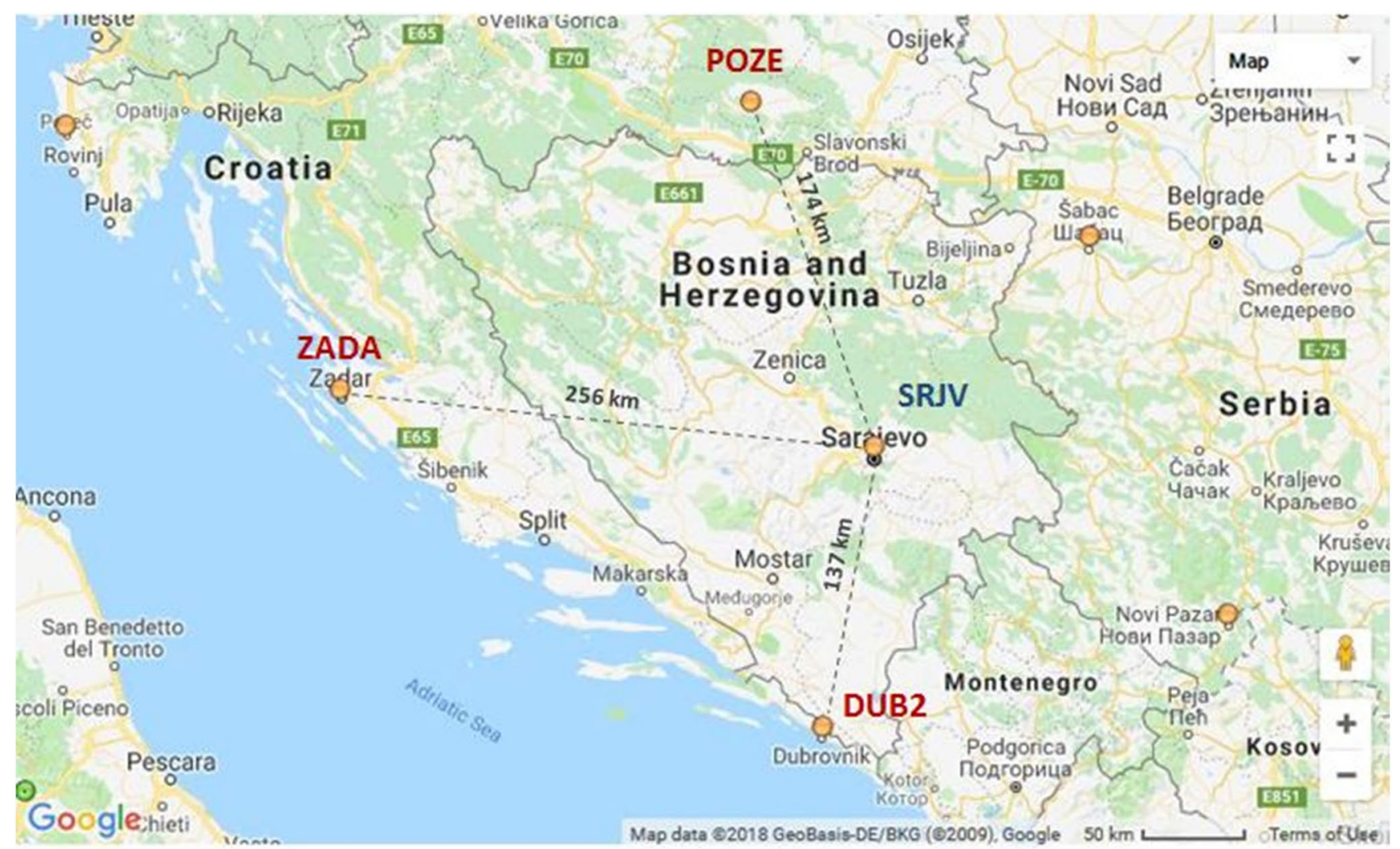

Fig. 1 EPN stations chosen for the PPP solution: SRJV (Sarajevo, B\&H), DUB2 (Dubrovnik, Croatia), POZE (Pozega, Croatia), ZADA (Zadar, Croatia) 
Table 2 List of VLF transmitters whose signals were used for monitor SRJV_ION 0436

\begin{tabular}{llll}
\hline VLF Station & Location & Country & Frequency $(\mathrm{Hz})$ \\
\hline DHO & Rhauderfehn & Germany & 23,400 \\
GBZ & Anthorn & UK & 19,580 \\
NSC & Sicily & Italy & 45,900 \\
\hline
\end{tabular}

Table 3 Major characteristics of the performed estimation

\begin{tabular}{ll}
\hline Software & Bernese v5.2 \\
\hline Processing period & 13.10.2014-31.10.2014 \\
Type of solution & 1-day static PPP Solution; \\
& 1-Day kinematic PPP Solution \\
Satellite system & GPS/GLO \\
Observations & Phase and Code \\
A priori orbits/EOPs/CLK & Final CODE Products \\
Reference frame & IGb08 \\
\hline
\end{tabular}

Observation data were downloaded from the Stanford Solar Center database [26]. When interpreting and analysing the collected data, it is important to compare it with X-ray flux plots obtained from GOES [27], as well as with the catalogue of solar events [28].

For TEC estimation, carrier phase GNSS measurements of GPS and GLONASS were applied. Biases were estimated and reduced from the measurements. Calibration of slant TEC (STEC) was performed following the Ciraolo methodology [29] with a sampling rate of $300 \mathrm{~s}$. The STEC were estimated for all visible satellites, applying elevation mask of $10^{\circ}$. The ionosphere was approximated with single-layer model (SLM) [11], with the assumption that all free electrons were concentrated in an infinitely thin layer at a fixed height of $400 \mathrm{~km}$ above the Earth's surface. Slant TEC was mapped using SLM to the vertical one (VTEC).

Static and kinematic precise point positioning was conducted with the scientific software Bernese v.5.2 and by applying $L 3$ ionosphere-free linear combination [30] (Table 3). Static positioning results (daily, $24 \mathrm{~h}$ ) and kinematic positioning results (sampling rate of $300 \mathrm{~s}$ ) were compared to the EPN weekly combined solution [31] in order to investigate deviations of estimated coordinates. The resulting output files contain the station positioning estimates in the earth-centred, earth-fixed (ECEF) Cartesian coordinate system $(x, y, z)$. The same applies for the EPN weekly combined solution, which means that the coordinate solution is given in xyz components. Hence, a transformation of both solutions (PPP and EPN) was performed to obtain those coordinate values in the local East, North, Up (ENU) components (Eq. 2.1)
$\left[\begin{array}{c}E \\ N \\ U\end{array}\right]_{i}=R_{1}\left[\frac{\pi}{2}-\varphi_{i}\right] R_{3}\left[\frac{\pi}{2}+\lambda_{i}\right]\left[\begin{array}{l}x \\ y \\ z\end{array}\right]_{i}$

where index $i$ refers to the corresponding EPN station and $\varphi_{i}, \lambda_{i}$ to its latitude and longitude. The transformation matrix is given with the following equation (Eq. 2.2):

$R_{1}\left[\frac{\pi}{2}-\varphi_{i}\right] \quad R_{3}\left[\frac{\pi}{2}+\lambda_{i}\right]=\left[\begin{array}{ccc}-\sin \lambda_{i} & \cos \lambda_{i} & 0 \\ -\cos \lambda_{i} \sin \varphi_{i} & -\sin \lambda_{i} \sin \varphi_{i} & \cos \varphi_{i} \\ \cos \lambda_{i} \cos \varphi_{i} & \sin \lambda_{i} \cos \varphi_{i} & \sin \varphi_{i}\end{array}\right]$

The differences of the static PPP solution for the EPN stations with respect to the EPN weekly combined solution in ENU components were calculated using equation (Eq. 2.3) [32].

$\left[\begin{array}{l}d_{E} \\ d_{N} \\ d_{U}\end{array}\right]_{i}=\left[\begin{array}{c}E \\ N \\ U\end{array}\right]_{\mathrm{PPP}_{i}}-\left[\begin{array}{c}E \\ N \\ U\end{array}\right]_{\text {EPN weekly comined }}$

The corresponding standard deviations of the PPP coordinate solution were calculated using Eq. 2.4 for each GPS week separately:

$\sigma_{U_{i}}=\sqrt{\frac{\sum_{k=1}^{n}\left(U_{\text {PPP }_{i}}-U_{\text {EPN weekly combined }}\right)^{2}}{n-1}}=\sqrt{\frac{\sum_{k=1}^{n} d_{U_{i}}}{n-1}}$,

where index $k$ is the counter for the day within a GPS week, and index $n$ refers to the total amount of days within each GPS week covered by the investigation period.

\section{Results}

\subsection{Space weather indices}

Figure 2 represents indices of space weather in October 2014, which includes indices of solar activity (SN and F10.7), solar wind speed (SW) and geomagnetic indices (Dst, Kp and Ap). High number of sunspots (from 100 to near 140 ) was reached in the beginning of the month (01st to 05 th) as well as in the second half of the month (from 20th to 29th). Solar radio emissions were significantly high (more than $150 \mathrm{sfu}$ ) from 18th to 29th October. In the first period of the month, the solar wind was mostly at nominal conditions with the wind speed between 300 and $400 \mathrm{~km} / \mathrm{s}$. From 13th, solar wind speed increased gradually and was the highest on $21 \mathrm{st}$ with near $700 \mathrm{~km} / \mathrm{s}$. Afterwards, its value decreased and was around $400 \mathrm{~km} / \mathrm{s}$ until 
Fig. 2 Indices of space weather (from up to button): sunspot number (SN), solar radio flux F10.7 in sfu (solar flux units), solar wind (SW) plasma speed in $\mathrm{km} / \mathrm{s}$, Dst (disturbance storm time) in $\mathrm{nT}$ (nano-Tesla), Kp (Quiet $K<3$, Moderate $3 \leq K<4$, Active $4 \leq K<5$, Storm $5 \leq K$ ) and its equivalent $A p$ in $n T$. High solar activity recorded in the second half of the month, with the peak from 20th to 27th October. Second half of the month also categorized with some unsettled conditions in geomagnetic field, with few isolated active episodes recorded
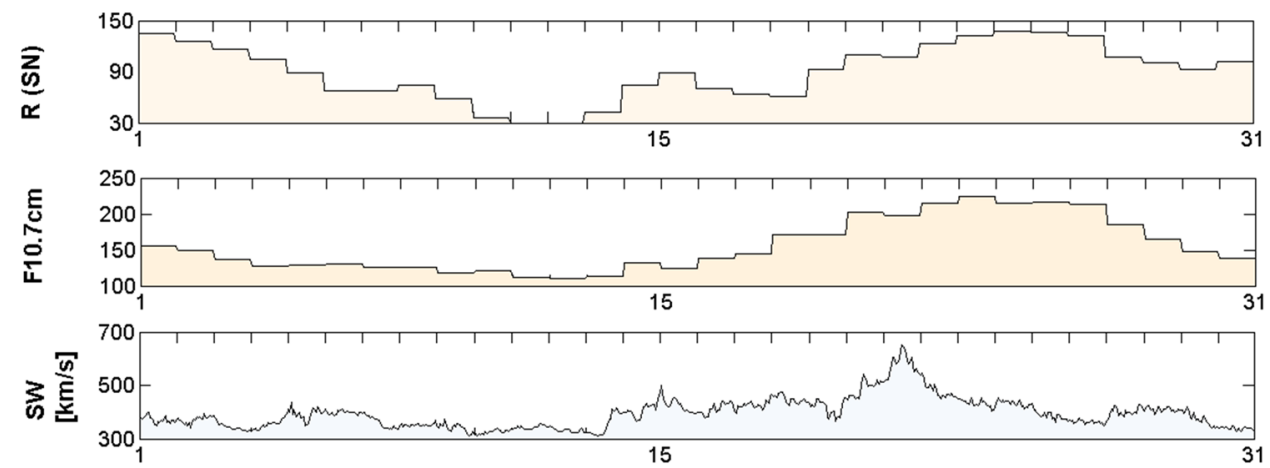

(a)
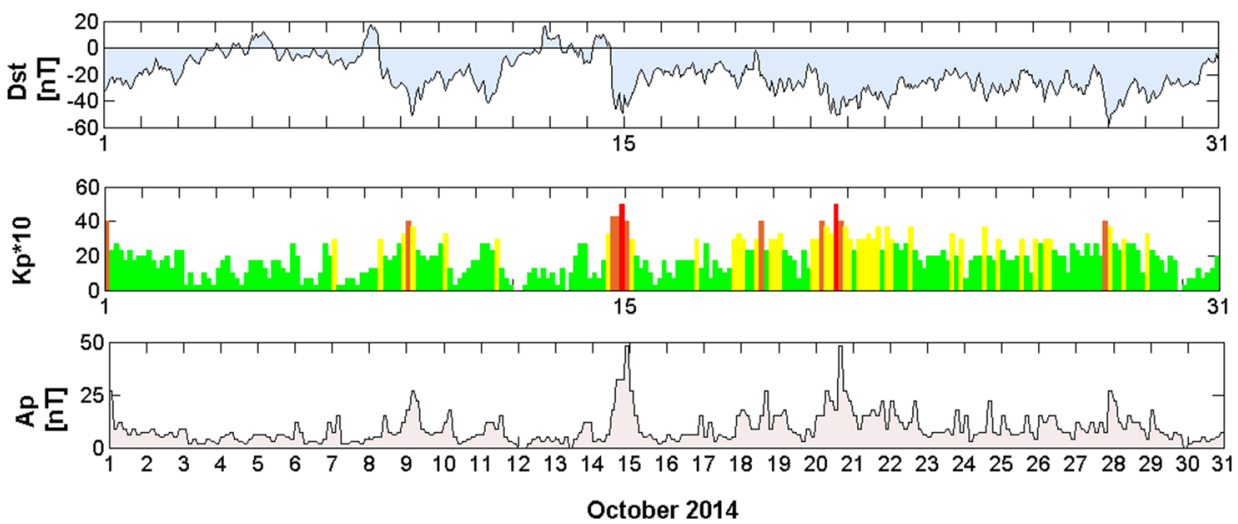

(b)

\begin{tabular}{lc}
\hline Solar flare class & Amount \\
\hline X & 6 \\
M & 41 \\
C & 146 \\
B & 9 \\
Total & 202 \\
\hline
\end{tabular}

Table 4 Total amount of solar flares, divided into the main classes, occurred in October 2014

the end of the month. Geomagnetic conditions were quite unsettled during the month, with some isolated active episodes recorded, mostly in the second part of the month (from 14th October). Minor geomagnetic storms were observed on 14th, 15th and 21 st October.

\subsection{Solar flares detection}

In this study, $\mathrm{X}$ and $\mathrm{M}$ solar flares were analysed that occurred during daytime, considering the local time of the space weather monitor SRJV_ION 0436. There is no ionization caused by the Sun during night hours; there is only a small amount of ionization caused by cosmic rays. Below are statistics with the total number of solar flares occurred on Sun's surface in October 2014 (Table 4). Details of the
$\mathrm{X}$ and $\mathrm{M}$ flares observed during daytime in October 2014 (a total of 17) with the corresponding characteristics are shown in Table 5. The list of space weather events in 2014 can be found on NOAA's Space Weather Prediction Center database [33]. Enhanced solar activity was noticed in the second half of October.

All observed solar flares originated in the same active region, i.e. sunspot NOAA 2192 (Fig. 3). It was the largest sunspot (diameter $>100,000 \mathrm{~km}$ ) measured in solar cycle 24 [34] and the largest one observed since November 18, 1990 [35]. According to the NOAA reports, NOAA 2192 reached a maximum sunspot area on 26th October, which is comparable to 16 times the Earth's surface area [36]. However, there were neither obvious coronal mass ejections (CMEs) nor increase in high-energetic particles associated with all the $X$ class flares produced by NOAA 2192 , except for the brief high-frequency radio blackouts resulting from the intense $X$-ray radiation [36].

Days, when the strongest solar flares are detected (orange-coloured rows Table 5), are shown in Fig. 4, presenting a comparison between the space weather monitor SRJV_ION data and GOES X-ray plots. It showed an overall agreement between the data (considering the daytime), where occasional noises (which may occur due to the interference with other nearby devices) are ignored. 
Table 5 List of solar flares occurred in October 2014, considering local daytime of the monitor's (SRJV_ION 0436) location

\begin{tabular}{|c|c|c|c|c|c|c|c|c|c|c|}
\hline Date & Event & Begin & Max & End & Obs & Q & Type & Loc/Frq & Particulars & Reg \\
\hline 09.10 .2014 & 940 & $06: 48$ & $06: 59$ & 07:06 & G15 & 5 & $X R A$ & $1-8 A$ & $\begin{array}{l}M 1.2 \\
7.6 E-03\end{array}$ & 2182 \\
\hline 16.10 .2014 & 2220 & $12: 58$ & $13: 03$ & $13: 05$ & G15 & 5 & XRA & $1-8 \mathrm{~A}$ & $\begin{array}{l}M 4.3 \\
8.2 E-03\end{array}$ & 2192 \\
\hline 18.10 .2014 & 3070 & 07:02 & $07: 58$ & 08:49 & G15 & 5 & XRA & $1-8 \mathrm{~A}$ & $\begin{array}{l}M 1.6 \\
6.6 \mathrm{E}-02\end{array}$ & 2192 \\
\hline 19.10.2014 & 3420 & $04: 17$ & 05:03 & $05: 48$ & G15 & 5 & XRA & $1-8 A$ & $\begin{array}{l}X 1.1 \\
3.9 E-01\end{array}$ & 2192 \\
\hline 20.10 .2014 & 3860 & 09:00 & 09:11 & 09:20 & G15 & 5 & XRA & $1-8 \mathrm{~A}$ & $\begin{array}{l}\text { M3.9 } \\
2.8 \mathrm{E}-02\end{array}$ & 2192 \\
\hline 21.10 .2014 & 4390 & $13: 35$ & $13: 38$ & $13: 40$ & G15 & 5 & XRA & $1-8 \mathrm{~A}$ & $\begin{array}{l}M 1.2 \\
1.4 E-03\end{array}$ & \\
\hline 22.10 .2014 & 4650 & 05:11 & $05: 17$ & 05:21 & G15 & 5 & XRA & $1-8 \mathrm{~A}$ & $\begin{array}{l}M 2.7 \\
1.0 E-02\end{array}$ & 2192 \\
\hline 22.10 .2014 & 4800 & $14: 02$ & $14: 28$ & $14: 50$ & G15 & 5 & $X R A$ & $1-8 A$ & $\begin{array}{l}X 1.6 \\
3.4 E-01\end{array}$ & 2192 \\
\hline 23.10 .2014 & 5030 & 09:44 & $09: 50$ & 09:56 & G15 & 5 & XRA & $1-8 \mathrm{~A}$ & $\begin{array}{l}\text { M1.1 } \\
5.3 E-03\end{array}$ & 2192 \\
\hline 24.10 .2014 & 5260 & $07: 37$ & $07: 48$ & 07:53 & G15 & 5 & XRA & $1-8 \mathrm{~A}$ & $\begin{array}{l}\text { M4.0 } \\
2.3 E-02\end{array}$ & 2192 \\
\hline 26.10 .2014 & 5750 & $10: 04$ & $10: 56$ & 11:18 & G15 & 5 & XRA & $1-8 A$ & $\begin{array}{l}X 2.0 \\
3.4 E-01\end{array}$ & 2192 \\
\hline 27.10 .2014 & 6050 & 09:59 & 10:09 & $10: 26$ & G15 & 5 & XRA & $1-8 \mathrm{~A}$ & $\begin{array}{l}\text { M6.7 } \\
9.3 E-02\end{array}$ & 2192 \\
\hline 27.10 .2014 & 6060 & $14: 12$ & $14: 47$ & 15:09 & G15 & 5 & XRA & $1-8 A$ & $\begin{array}{l}X 2.0 \\
4.5 E-01\end{array}$ & 2192 \\
\hline 28.10 .2014 & 6330 & $13: 54$ & $14: 06$ & $14: 23$ & G15 & 5 & XRA & $1-8 \mathrm{~A}$ & $\begin{array}{l}M 1.6 \\
2.0 \mathrm{E}-02\end{array}$ & 2192 \\
\hline 29.10 .2014 & 6500 & 06:03 & $08: 20$ & $08: 52$ & G15 & 5 & XRA & $1-8 \mathrm{~A}$ & $\begin{array}{l}\mathrm{M} 1.0 \\
7.6 \mathrm{E}-02\end{array}$ & 2192 \\
\hline 29.10 .2014 & 6550 & 09:54 & 10:01 & $10: 06$ & G15 & 5 & XRA & $1-8 \mathrm{~A}$ & $\begin{array}{l}\mathrm{M} 1.2 \\
5.5 \mathrm{E}-03\end{array}$ & 2192 \\
\hline 29.10 .2014 & 6570 & 1424 & 1433 & 1451 & G15 & 5 & XRA & $1-8 \mathrm{~A}$ & $\begin{array}{l}\text { M1.4 } \\
1.9 \mathrm{E}-02\end{array}$ & 2192 \\
\hline
\end{tabular}

Italics rows indicate inactivity of the monitor; hence, those flares could not be detected. Inactivity of the monitor can be caused either by short power outage or by technical problems of the PC to which the monitor is connected. Bold rows indicate the days when strongest solar flares of class $\mathrm{X}$ are detected

\subsection{Ionosphere TEC variability}

lonosphere VTEC values are estimated with sampling rate of $300 \mathrm{~s}$ for EPN stations SRJV, DUB2, POZE and ZADA for October 2014 (Fig. 5). Maps of VTEC values (Fig. 6) are created for stations DUB2, POZE and ZADA for a period from 13 th to 31 st October. During $24 \mathrm{~h}$, VTEC values were higher from 09:00 to 16:00, where a peak is reached around local noon, i.e. from about 10:00 to 14:00 ( 30 to 40 TECU). In the second half of the month, starting from 24th, higher VTEC values are observed for all stations during high solar activity (Fig. 2). VTEC increase is especially pronounced from 26th to 28th (VTEC > 50 TECU) during high level of solar activity (F10.7 150 sfu), characterized with the occurrence of two strongest flares in October 2014 of class X2.0 (on 26th and 27th).
Due to reason that solar flare causes sudden ionization of the earth's ionosphere in the sunlit hemisphere within short intervals of time, i.e. during and short after solar flare's occurrence, in further analysis, VTEC values during days of strong solar flares are taken into consideration, paying attention to the occurring time of flare (UTC). The strongest solar flares of class $X$ occurred on 19th (X1.1), 22nd (X1.6), 26th (X2.2) and 27th (X2.2) October. STEC values estimated for each visible satellite (blue line-GPS, red line-GLONASS) and VTEC values (black line) for EPN station ZADA are presented on Fig. 7 for days of the occurrence of solar flares of class $X$. During the time period of the occurrence of solar flares, class $X$ (pink box) and class $M$ (light blue box) enhancement of VTEC and STEC values for some satellites can be observed (Fig. 7a-d), when they are mutually compared. 


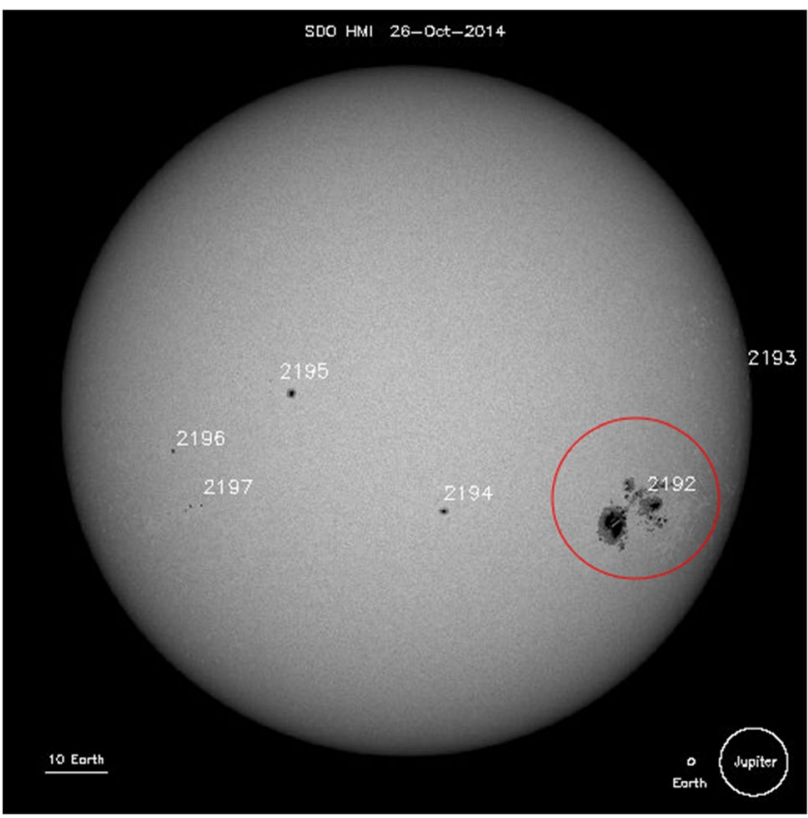

Fig. 3 Sun's active regions for the day 26.10.2014, including the active region 2192 on the right side in red circle [37]. Sizes of the Earth and Jupiter are shown in the right lower corner for comparison

Figure 8 shows VTEC on 26th and 27th (both days with X2.0 solar flares and additional M6.7 flare on 27th) and VTEC on a day before 25th, which is a day without solar flares used for comparison and analysis of VTEC change. Increase in VTEC values on 26th and 27th during a day is registered from about 10:00 to about 15:00 and reached to near 10 TECU compared to VTEC on 25th. On 26th, higher VTEC values are observed from 10:10 to near noon time, while solar flare X2.0 lasted from 10:04 until 11:18. On 27th, smaller VTEC enhancement is seen before the noon, which also covers the period of M6.7 flare's occurrence, while higher VTEC values are observed after the noon until around 15:30, where end time of second solar flare X2.0 was 15:09. Those VTEC variations can be related to the influence of solar flares and high solar activity.

\subsection{Precise Point Positioning}

The period of enhanced solar activity during the month of October was investigated (13.10.2014-31.10.2014), and static and kinematic PPP was performed using observation data of EPN stations. The differences of the static PPP solution for the EPN stations with respect to the EPN weekly combined solution, obtained applying Eqs. 2.1-2.3, are shown in Fig. 9.
Higher deviations in the Up component for station SRJV are observed from the 19th October $(2.7 \mathrm{~cm}$ in absolute), when the first solar flare of class $X$ occurred (X1.1). The excessive residual jump visible on the 22 nd October is too high $(\sim 10 \mathrm{~cm})$ to be attributed only to the more pronounced solar activity, especially when compared to the solutions calculated for the remaining stations DUB2, POZE and ZADA (maximum deviation in Up component $\sim 2 \mathrm{~cm}$ in absolute) and the fact that after the 23rd October until the end of the month no observation data were available for SRJV. It is assumed that the cause for this coordinate solution is of technical nature, i.e. related either to the station receiver or antenna. Therefore, the estimation for the 22nd October will not be taken into account in the further analysis and will be considered as an outlier. For the remaining stations, a considerable deviation increase in the Up component was observed from 22nd October, when the second $X$ flare occurred $(X 1.6)$. Until the end of the month, the differences retain higher, compared to the period before the 22nd October. For this day, the deviations for DUB2, POZE and ZADA amounted, respectively, 11,7 and $14.5 \mathrm{~mm}$ in absolute.

As it can be seen from Fig. 9, coordinate variations in Up component are significantly higher during stronger solar flare activity, compared to the remaining components (East and North). Therefore, only Up components were used for each station to analyse their coordinate variations (Fig. 10). In order to examine their correlation with stronger solar activity, days when the strongest solar flares of class $\mathrm{M}$ and $\mathrm{X}$ occurred were marked and labelled with the corresponding flare class. Solar flare attributes were taken from Table 5. On 16th October, one of the stronger solar flares of class M occurred (M4.3) (Table 5). Even though this day belongs to the period during which the coordinate deviations are smaller compared to the period from 22nd October and further, slightly higher differences for DUB2, POZE and ZADA can still be observed compared to the days around it. The coordinate difference in the Up component for the stations DUB2, POZE and ZADA is $8.9 \mathrm{~mm}, 7.2 \mathrm{~mm}$ and $3.4 \mathrm{~mm}$ in absolute, respectively. On the 22nd October, when the stronger solar flare of class $X$ occurred (X1.6), following coordinate differences in the Up component for the stations DUB2, POZE and ZADA were observed, $11.06 \mathrm{~mm}, 6.96 \mathrm{~mm}$ and $14.47 \mathrm{~mm}$ in absolute, respectively. As shown in Fig. 10, two $X$ flares (both of class X2.0) occurred on the 26th and 27th October. The coordinate differences in Up component observed on the 26th for DUB2, POZE and ZADA are $13.39 \mathrm{~mm}, 4.05 \mathrm{~mm}$ and $10.17 \mathrm{~mm}$ in absolute, respectively, while for the 27th October, they amount to $13.96 \mathrm{~mm}, 5.44 \mathrm{~mm}$ and $12.94 \mathrm{~mm}$ in absolute, respectively. The highest deviations in Up component are noticed during the period of stronger solar flare events, i.e. the period from 22.10.2014 
Fig. 4 Comparison between SuperSID data collected by the monitor SRJV_ION 0436 (above) and GOES X-ray plots (below) for the days a) 18.20.10.2014, b) 26.-28.10.2014. The time period in the red boxes represents the local daytime of the monitor. Lines SuperSID data: green-DHO, dark blue-GBZ, light blueNSC

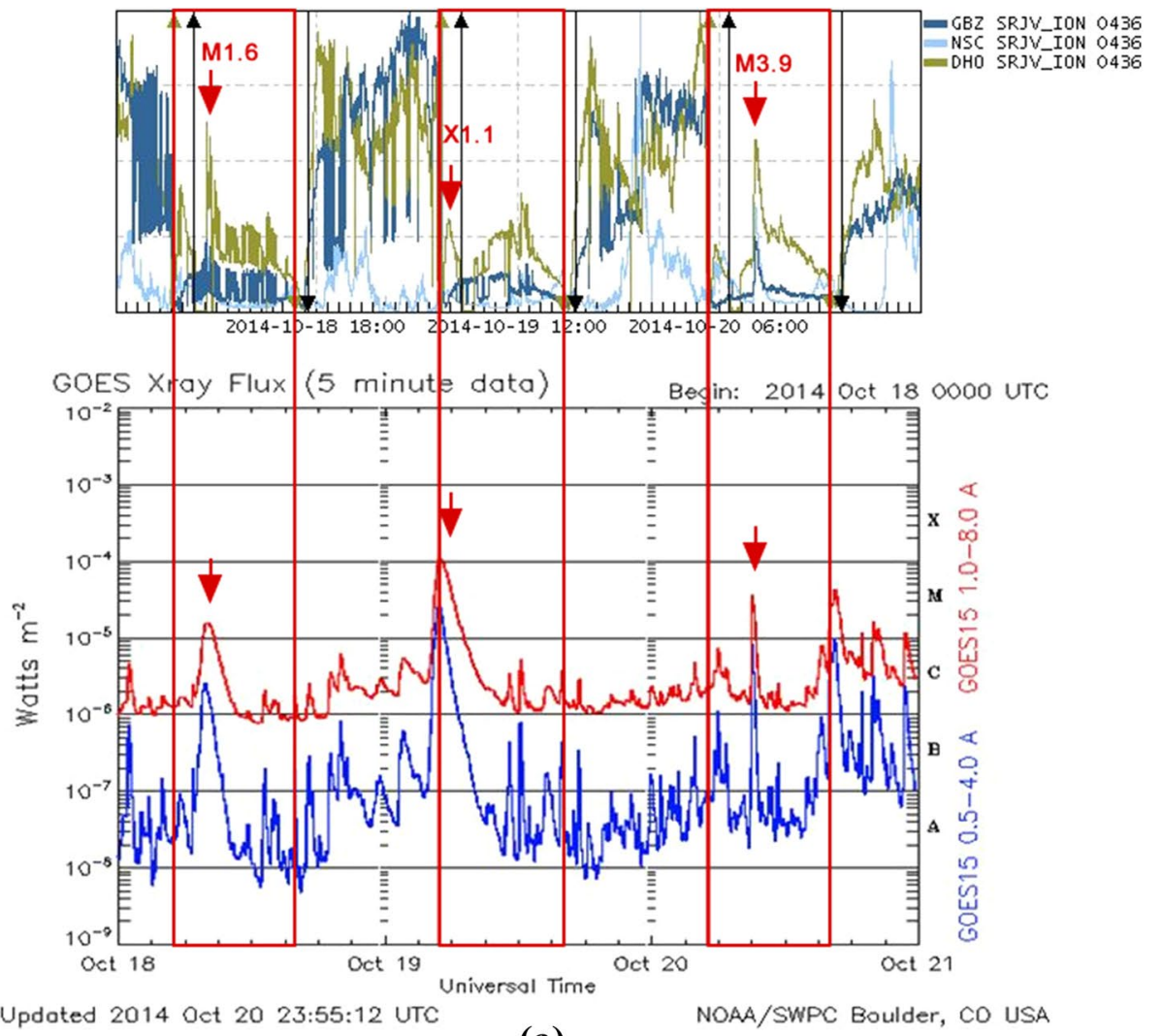

(a)

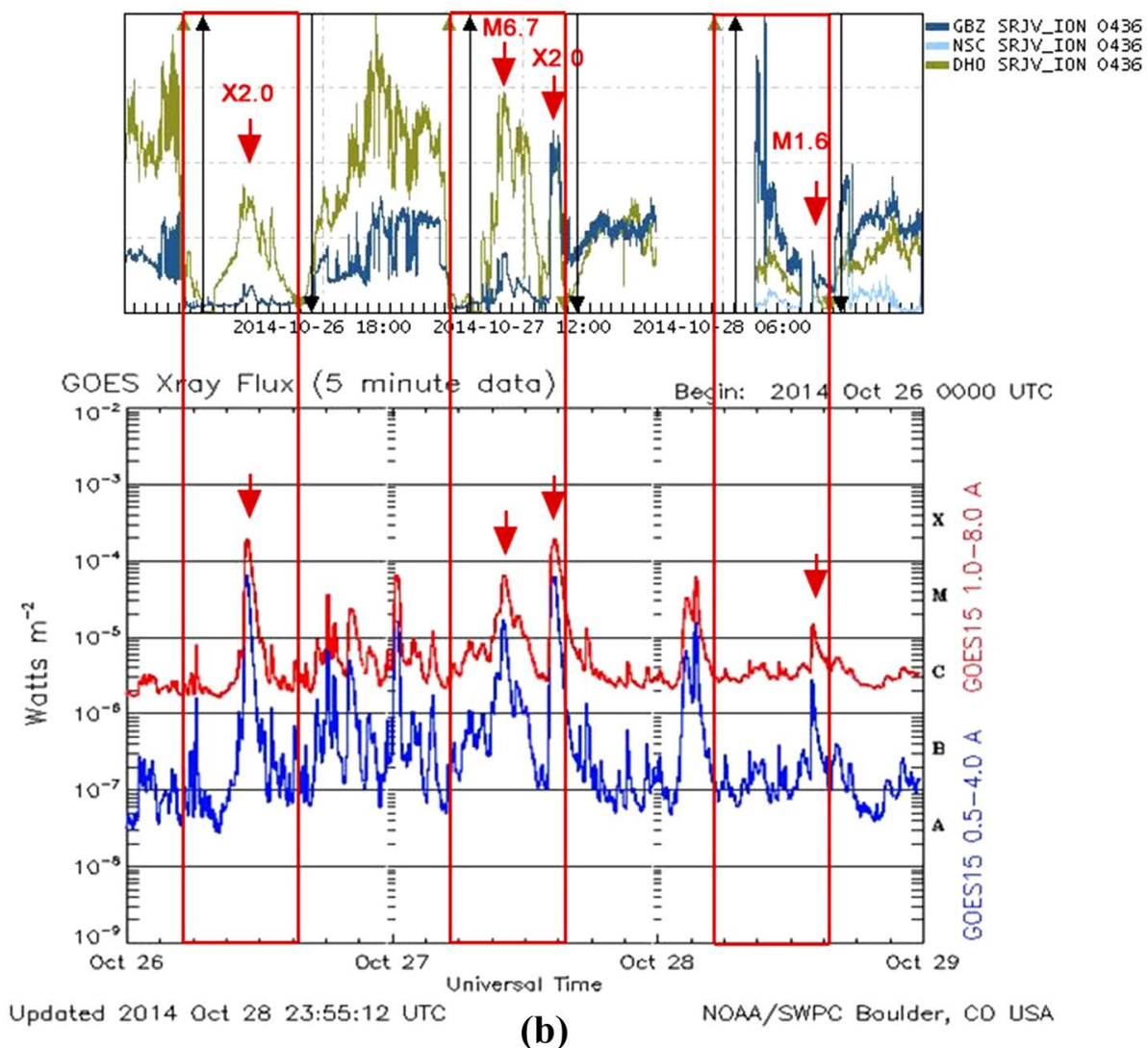


Fig. 5 Similar VTEC variability during October 2014 at four EPN stations (from up to bottom): SRJV, DUB2, POZE and ZADA. Maximum VTEC (recorded around local noon) is mostly 30 to 40 TECU. VTEC increase in last 10 days of the month, especially from 26th to 28th (>50 TECU), which coincides with the high level of solar activity and the period of occurrence of two strongest flares of class X2.0 (on 26th and 27th)
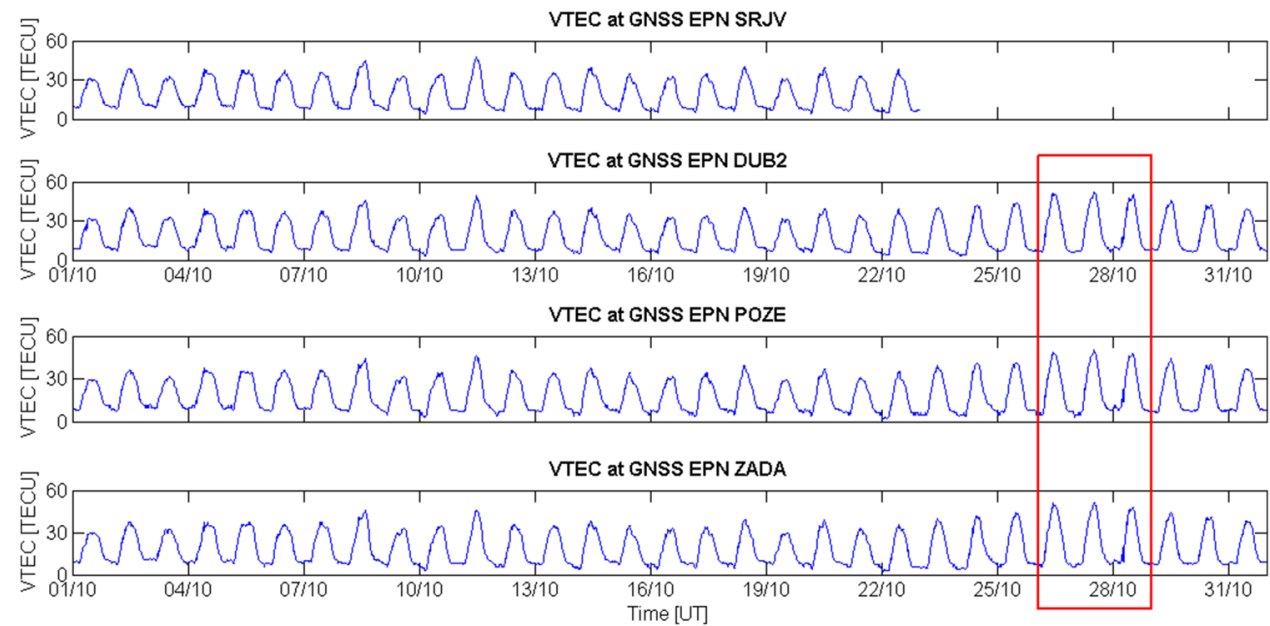

to 27.10.2014 for the stations DUB2, POZE and ZADA. During this period, the average coordinate differences of the three stations are, respectively, $14.50,7.17$ and $12.37 \mathrm{~mm}$ in absolute. The standard deviations of the static PPP coordinate solution in the Up component per GPS week are shown in Fig. 11 and calculated using Eq. 2.4.

In the further analysis, the investigated period 13.10.2014-31.10.2014 was divided into two sub-periods, 13.10.2014-21.10.2014 and 22.10.2014-31.10.2014, which refer to the time frames of minor and larger coordinate variations, respectively. (This is shown in Fig. 10.) Only EPN stations DUB2, POZE and ZADA were considered, since the lack of observation data for SRJV in the second time frame. In Table 6, statistics for the period from 13th until 22nd October and the period after 22nd October (including this day) are demonstrated. A graphical representation of the numerical data regarding the coordinate difference comparison between the periods of lower and higher solar activity is shown in Fig. 12. For both sub-periods, coordinate variations from Fig. 10 were converted into their absolute values. For each of the three EPN stations, the maximum, average and minimum values of the absolute coordinate variations were calculated to show a direct comparison between the periods of less and more pronounced solar flares and solar radio emissions. The absolute values of coordinate deviations for all stations show a significant increase in the Up component in the second time frame (22.10-31.10). The highest maximum, average and minimum differences show station DUB2 $(21 \mathrm{~mm}$, $13 \mathrm{~mm}$ and $9 \mathrm{~mm}$, respectively). These values are observed in the second time frame and are, compared to the first time frame, at least by two times higher in magnitude. A similar situation is with the remaining two stations, where coordinate differences are even more than three times higher in the second time frame (station ZADA). During the second period, occurred approximately twice more solar flares, compared to the first one.

A kinematic PPP was also performed in order to have better insight in the daily coordinate variations during enhanced solar activity. The period 22.10.2014-27.10.2014
Fig. 6 VTEC maps (13-31 October 2014). Significant increase in VTEC values visible during local noon starting from 23th and reached the peak from 26th to 28th at all three stations
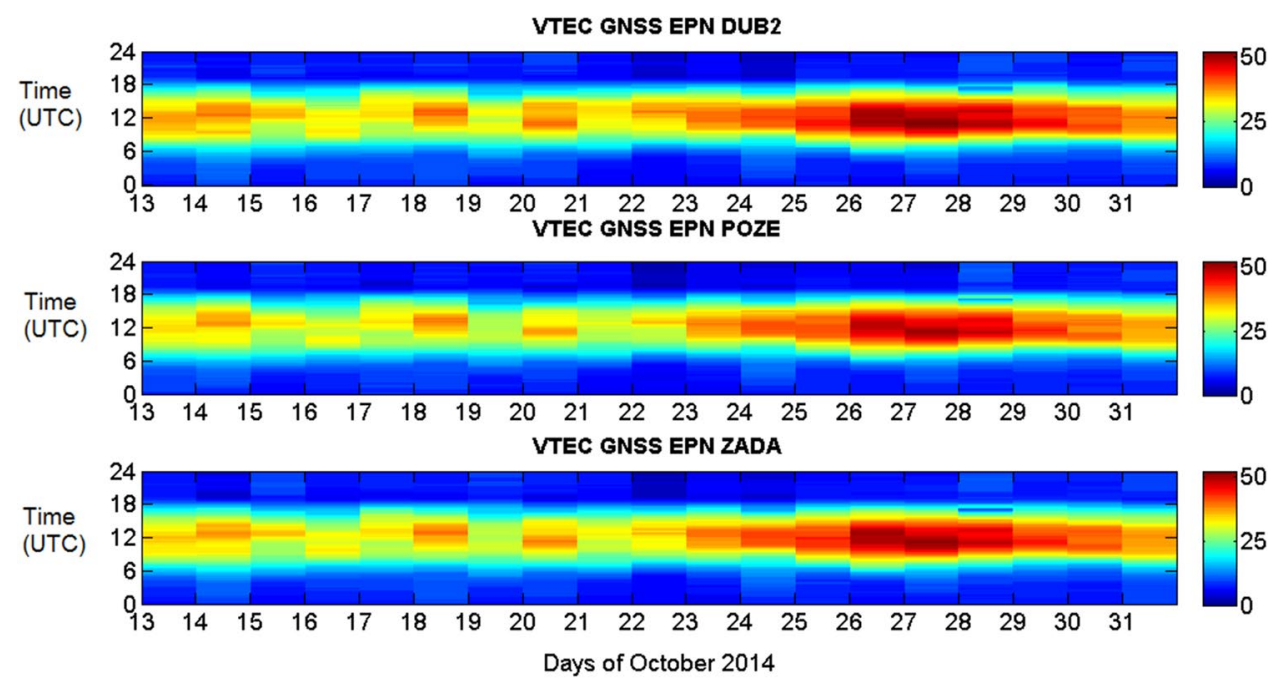

SN Applied Sciences A SPRINGER NATURE journal 


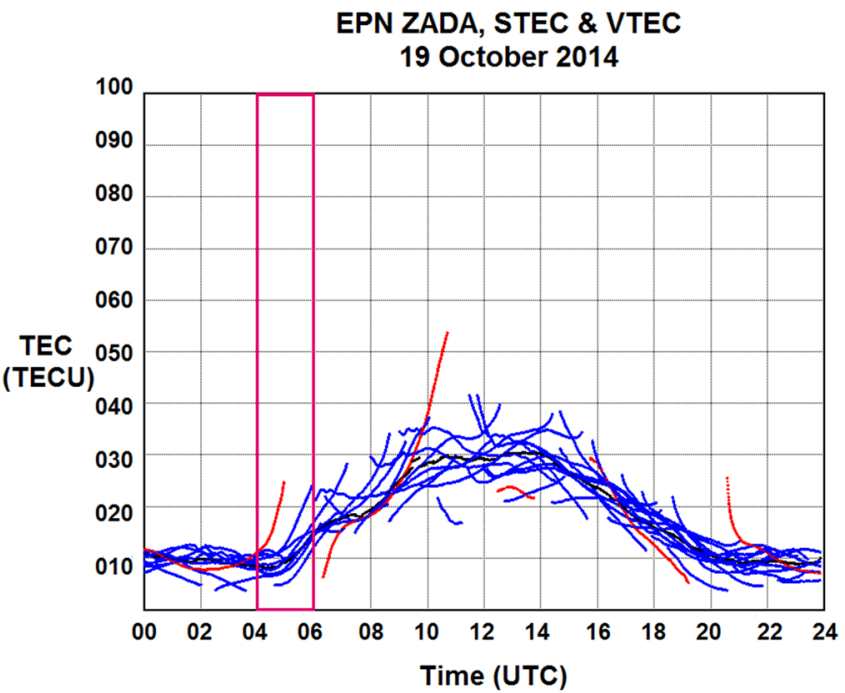

(a)

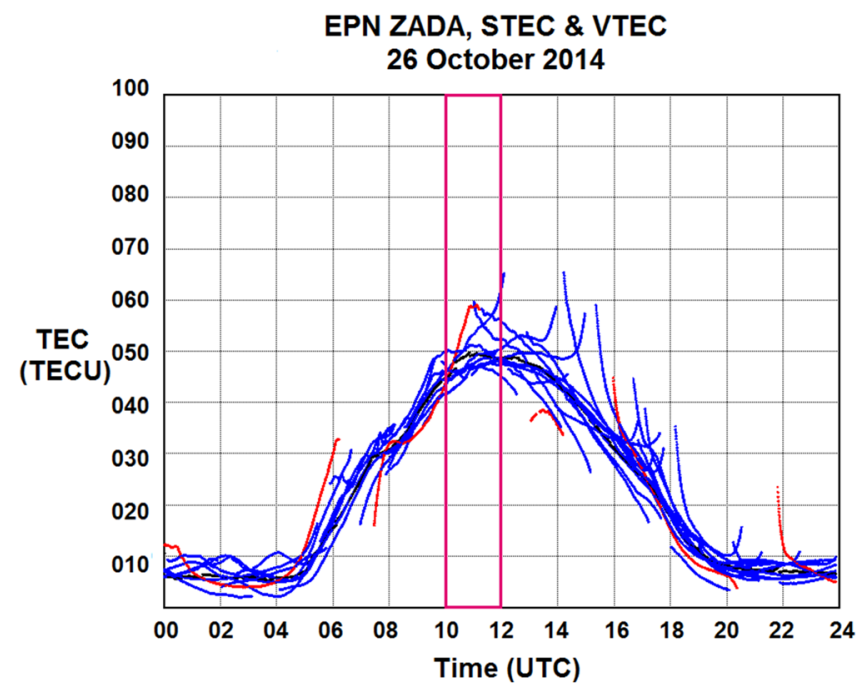

(c)

Fig. 7 STEC (blue lines-GPS and red lines-GLONASS) and VTEC (black line) values for the station ZADA for a 19/10 (X1.1 flare, begin time 04:17, end time 05:48 UT), b 22/10 (M2.7 flare, begin time $05: 11$, end time $05: 21 ; \mathrm{X} 1.6$ flare, begin time 14:02, end time 14:50 UT) c 26/10 (X2.0 flare, begin time 10:04, end time 11:18 UT)

(DOY 295-300) was chosen for kinematic solution for stations DUB2, POZE and ZADA during occurrence of three solar flares of class X. In Fig. 13, the daily coordinate variations for these stations in Up component are shown. They were obtained using the same approach as in the static PPP solution. First, using Eqs. 2.1 and 2.2, ECEF kinematic PPP coordinates were transformed into ENU components. After that, using Eq. 2.3, coordinate differences of the kinematic PPP solution were calculated w.r.t. the EPN weekly combined solution. The kinematic coordinate differences in Up component for all of three stations are mostly

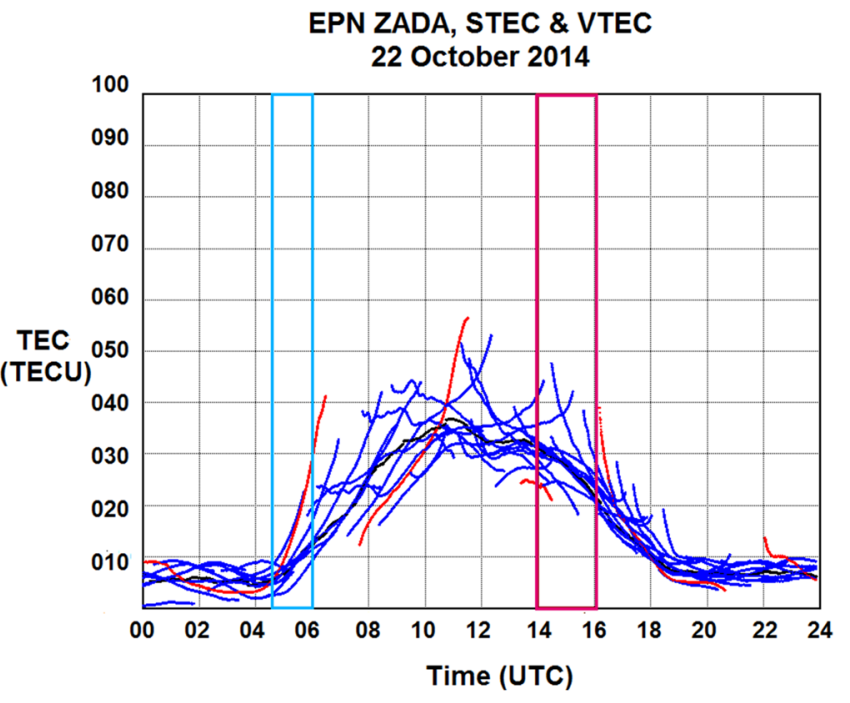

(b)

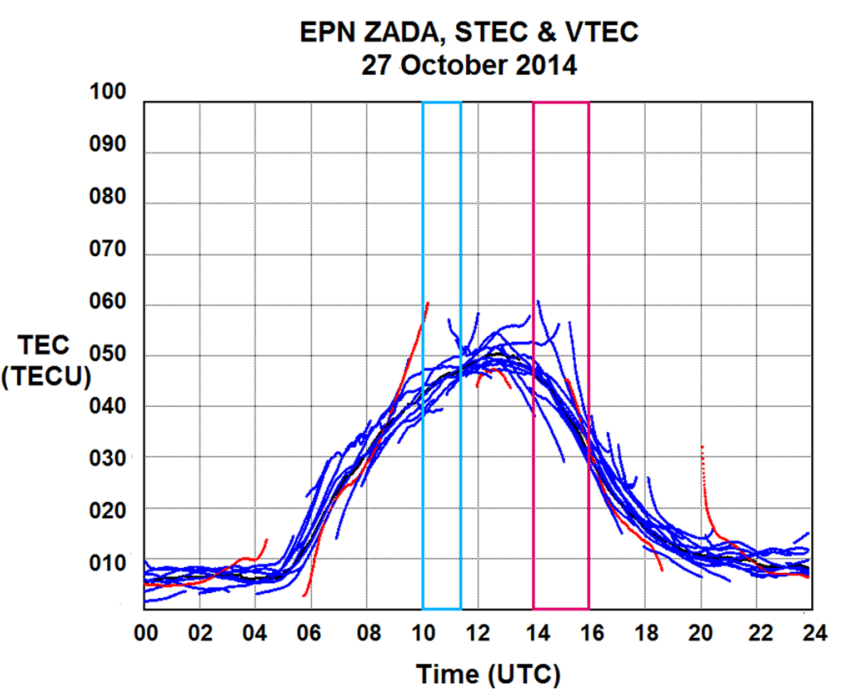

(d)

d 27/10 (M6.7 flare, begin time 09:59, end time 10:26; X2.0 flare, begin time 14:12, end time 15:09 UT). The time period in the pink box represents period of solar flare $X$ class, while light blue box is period of solar flare $\mathrm{M}$ class occurrence, including short time before and after

in a range of $50 \mathrm{~mm}$ in absolute, with some exceptions detected, especially for station DUB2. The maximum kinematic coordinate difference in Up component for DUB2 can be observed on the 24.10.2014 with $123.05 \mathrm{~mm}$, for POZE on the 25.10.2014 with $72.68 \mathrm{~mm}$ and for ZADA on the 22.10 .2014 with $110.61 \mathrm{~mm}$ in absolute, all during enhanced solar activity. 


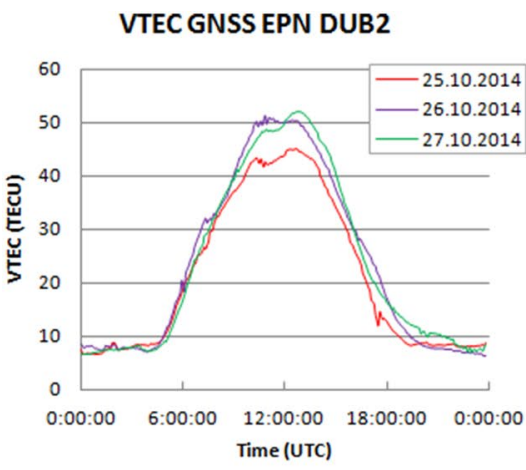

(a)
VTEC EPN GNSS POZE

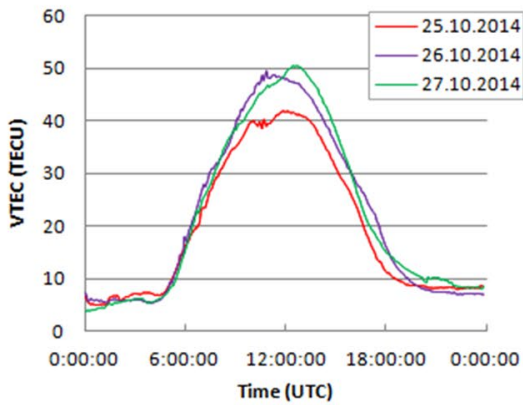

(b)
VTEC GNSS EPN ZADA

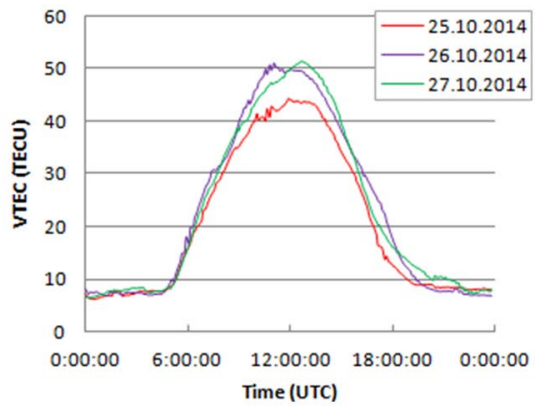

(c)
Fig. 8 VTEC values for the days of the strongest solar flares class X2.0. 26th (X2.0: begin time 10:04, end time 11:18) and 27th (X2.0: begin time 14:12, end time 15:09 and M6.7: begin time 09:59, end time 10:26) and for the previous day 25th, without solar flares. On 26th October, VTEC increase is before the noon from 10:10 to around 11:45, while on 27th October, first smaller VTEC enhancement is before the noon and higher VTEC values are after the noon to around 15:30 compared to VTEC of previous days (25th and 26th)
SRJV (2014 DOY 286 - 296)

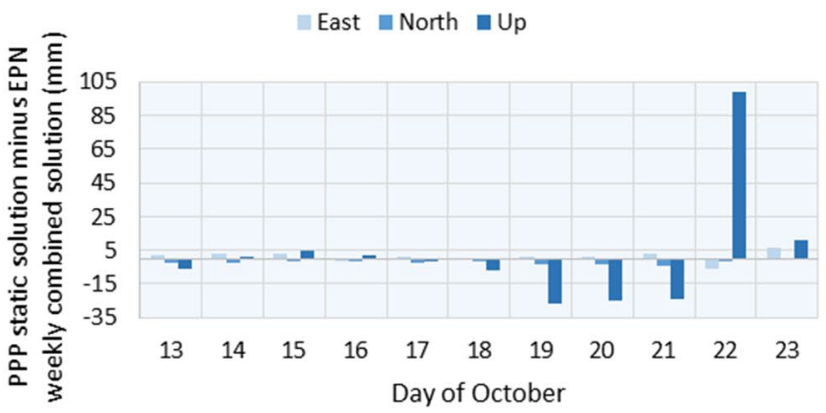

(a)

POZE (2014 DOY 286 - 304)

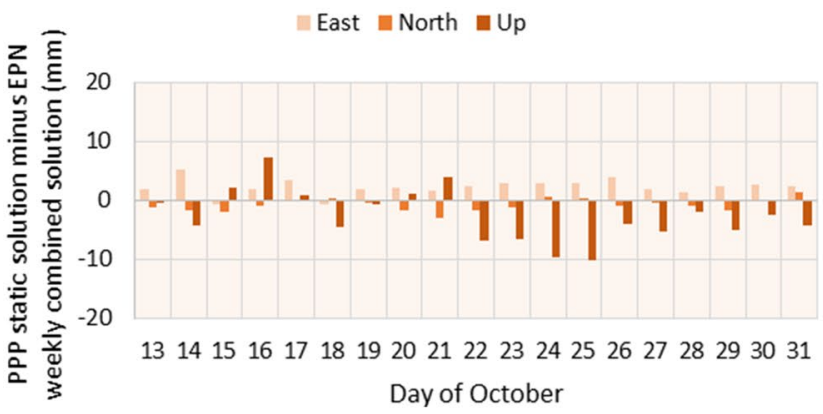

(c)

Fig. 9 Static PPP solution deviations in ENU components of EPN stations: a SRJV, b DUB2, c POZE and d ZADA, from the weekly EPN-combined coordinate solution. Since DUB2, POZE and ZADA show a coordinate deviation in the range of $\pm 20 \mathrm{~mm}(\mathbf{b}, \mathbf{c}, \mathbf{d})$, a dif-
DUB2 (2014 DOY 286 - 304)

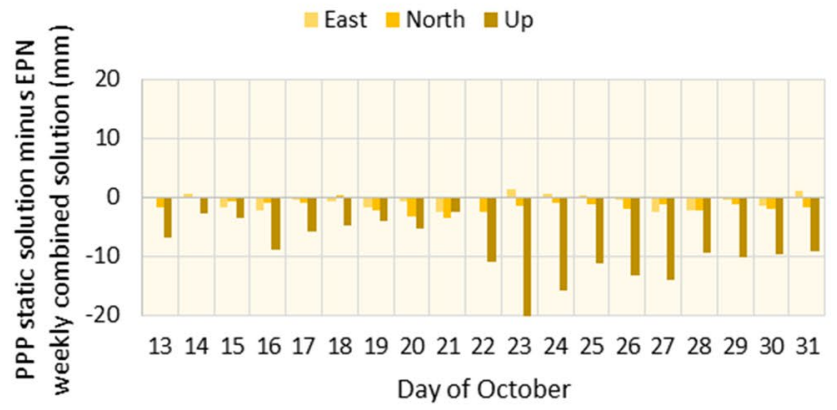

(b)

ZADA (2014 DOY 286 - 304)

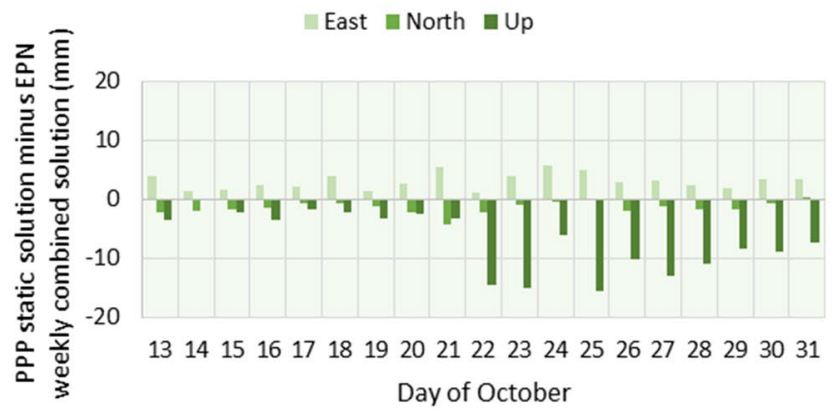

(d)

ferent axis scale has been used, compared to the axis scale applied for SRJV (a), in order to make deviations of positioning estimates of these stations more visible 
Fig. 10 Comparison of the static PPP coordinate w.r.t. the weekly EPN-combined solution in Up component for DUB2, POZE, ZADA and SRJV with the days of enhanced solar activity. The days with the strongest solar flares (stronger $\mathrm{M}$ flares and $X$ flares) during October 2014 are marked with red boxes and labelled with the corresponding solar flare class

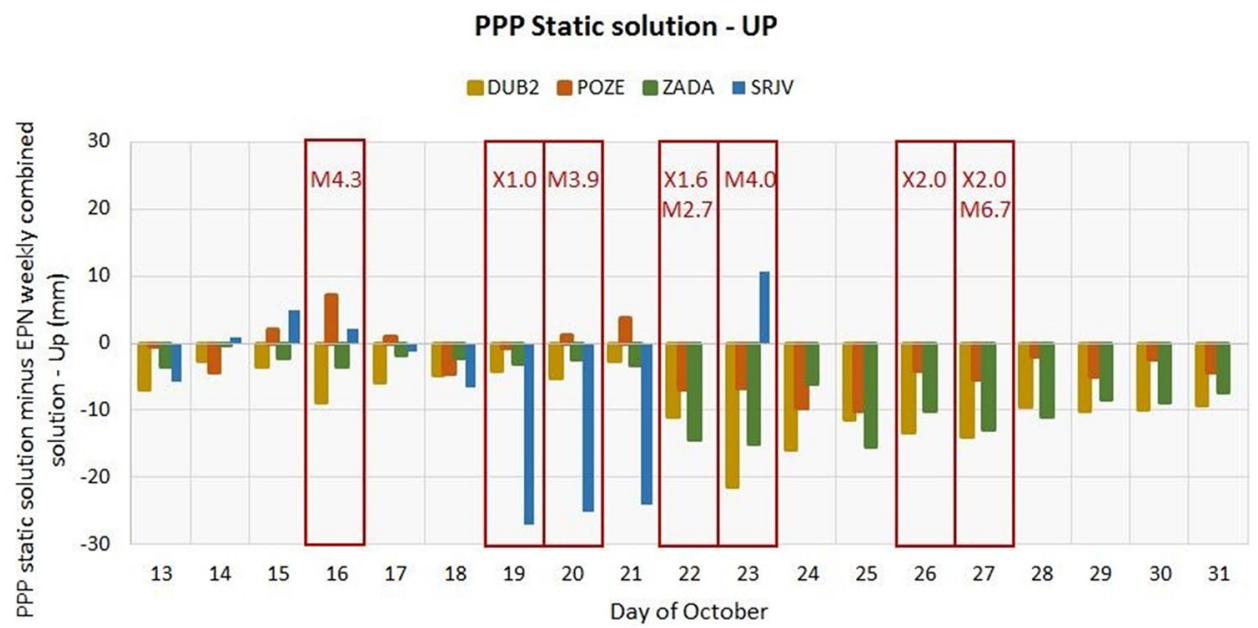

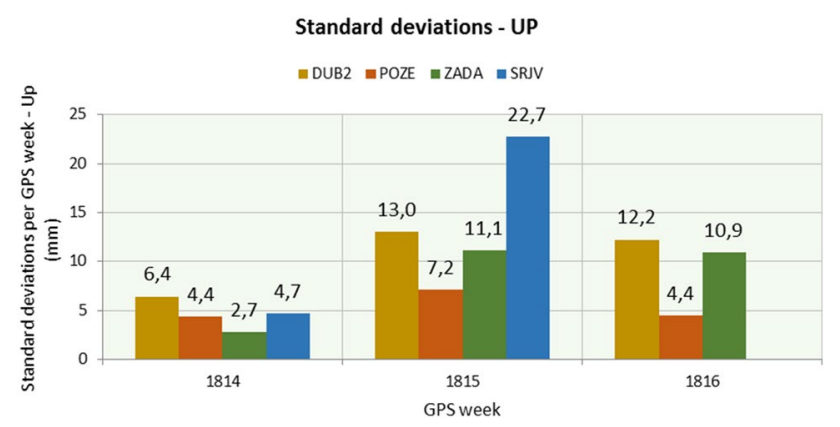

Fig. 11 Standard deviations in Up component per GPS week. In GPS week 1815 (19.10.-25.10.), it can be seen that the standard deviations for all stations increased by at least two times compared to GPS week 1814 (13.10.-18.10.). In the last-observed GPS week 1816 (26.10.-31.10.), a similar behaviour can be noticed for stations DUB2 and ZADA, while for POZE, the increase is visible on the submm level w.r.t. GPS week 1814

\section{Conclusion}

In this study, we examined activities on the Sun, conditions in space weather, state in ionosphere and their impacts on PPP coordinates estimates in the region of Western Balkan utilizing EPN GNSS stations in Bosnia and Herzegovina and Croatia. The study period was selected to be October 2014, due to increased level of solar activity, characterized with high number of intense solar flares of classes $M$ and $X$. The period of the investigation also refers to the maximum of solar cycle 24, which reached its peak in April 2014. Investigation includes study of various indices of space weather, study of solar flares using GOES X-ray flux data and their effects on ionospheric $D$ region using VLF radio waves as well as up to the ionospheric $F$ region using the estimated parameter TEC from GNSS measurements. Static and kinematic precise point positioning was performed to study artificial coordinate variations.

Solar radio emissions were significantly high in the second half of the month (from 18th), which was characterized by the occurrence of several strong solar flares of class $M$ and $X$. The geomagnetic conditions were quite unsettled, with few isolated active episodes in the second half of the month.

SuperSID monitor SRJV_ION 0436 registered sudden ionization in ionospheric $\mathrm{D}$ region over Western Balkan during local daytime. Good agreement is observed between SuperSID data, obtained by the space weather monitor SRJV_ION 0436, and GOES-derived X-ray flux plots.

Detected TEC variability was primarily under the influence of solar radiation and solar activity. Quiet geomagnetic conditions, presented during the most of the
Table 6 Comparison of maximum, average and minimum coordinate deviation values for Up component, as well as the comparison of solar flares during periods 13.10.2014-21.10.2014 and 22.10.2014 - 31.10.2014

\begin{tabular}{|c|c|c|c|c|c|c|}
\hline \multirow{2}{*}{$\begin{array}{l}\text { Time period } \\
\text { EPN Station }\end{array}$} & \multicolumn{3}{|c|}{$13.10 .2014-21.10 .2014$} & \multicolumn{3}{|c|}{$22.10 .2014-31.10 .2014$} \\
\hline & DUB2 & POZE & ZADA & DUB2 & POZE & ZADA \\
\hline \multicolumn{7}{|c|}{ Static PPP minus weekly EPN-combined solution-UP (mm) } \\
\hline Maximum & 8.93 & 7.19 & 3.51 & 21.43 & 10.11 & 15.49 \\
\hline Average & 4.98 & 2.80 & 2.47 & 12.57 & 5.67 & 10.97 \\
\hline Minimum & 2.63 & 0.52 & 0.12 & 9.28 & 1.97 & 6.05 \\
\hline \multicolumn{7}{|c|}{ Solar flares occurred } \\
\hline M class & & 4 & & & 8 & \\
\hline $\mathrm{X}$ class & & 1 & & & 3 & \\
\hline Total & & 5 & & & 11 & \\
\hline
\end{tabular}




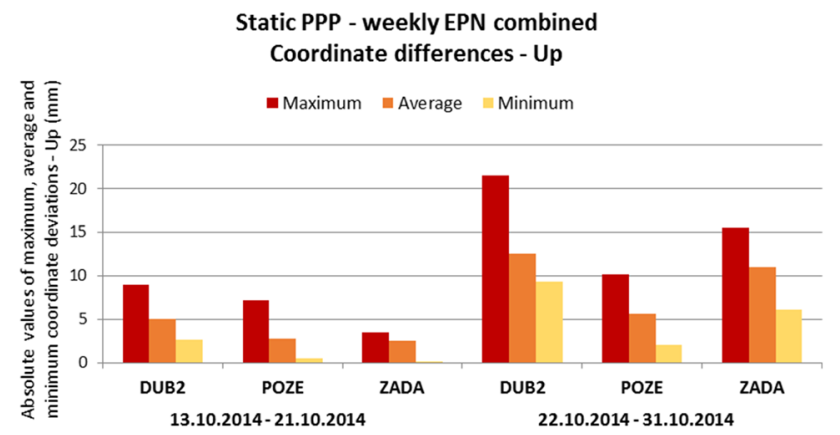

Fig. 12 Graphical representation of Table 6 showing the comparison of maximum, average and minimum coordinate deviation values in absolute for Up component during the periods 13.10.201421.10.2014 and 22.10.2014-31.10.2014

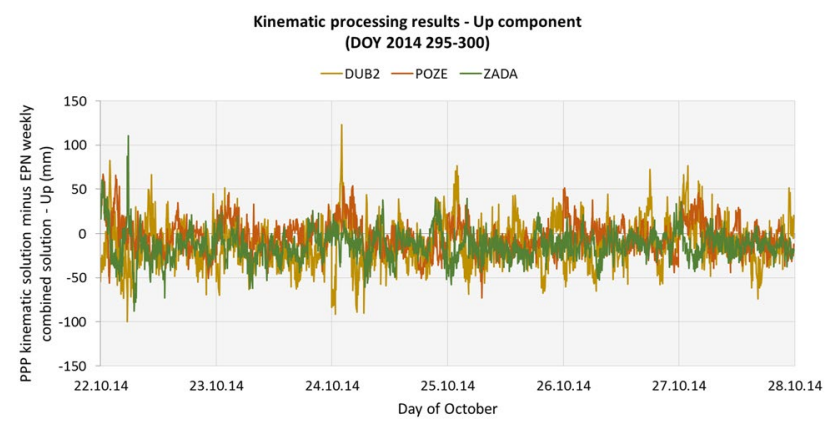

Fig. 13 Daily kinematic processing results in Up component-Kinematic PPP solution minus weekly EPN-combined solution. Most pronounced variations during this period can be noticed for station DUB2 (up to $120 \mathrm{~mm}$ ), which also showed the highest standard deviations in the static PPP solution

investigated periods, allowed to relate the detected ionosphere TEC variations to solar radio emissions and solar flare occurrence. Ionosphere TEC variability was more pronounced in the second half of the month, from 23th October. In particular, significant TEC increase (maximum TEC > 50 TECU) is observed from 26th to 28th, which coincides with the period of high solar radio emissions (F10.7) connected to the occurrence of two strongest flares of class X2.0 in October 2014 (on 26th and 27th). Further analysis shows additional enhancement in TEC values on 26th and 27th October during the occurring time of solar flares of classes M6.7 and X2.0.

Smaller coordinate differences with respect to the weekly EPN-combined solution for all used EPN stations were noticed in the period before stronger solar flares. Differences for the period after the appearance of the first stronger solar flares and during the period of the high solar activity show an increase in magnitude by at least two times. Station SRJV needed to be excluded in the further analysis, but comparing the coordinate differences with the solar activity in October, a similar pattern can be seen.
Here, the first increase in the coordinate variations was noticed on the 19th October when the first $X$ solar flare (X1.1) in this month occurred. All other stations showed this visible increase in the variation on the 22nd October, when the second X solar flare (X1.6) was registered, preceded by a stronger $M$ solar flare (M2.7) on the same day. During second time frame from 22nd October until the end of the investigated period, coordinate deviations of three EPN stations (DUB2, POZE and ZADA) remained higher, at least by two times, compared to the first time frame. It also needs to be noted that approximately twice more strong solar flares occurred in the second time frame.

It can be assumed that the high coordinate deviation on the station SRJV on 22nd October is not related to the enhanced solar activity, but is associated to a problem of technical nature. The unavailability of the observation data 2 days after might be an indicator for this assumption.

Results show an overall good agreement between the observed activities on the Sun, conditions in the ionosphere, SuperSID-derived data, GNSS-derived TEC and performed PPP coordinates solutions. Enhancement in solar radio emission and occurrence of strong solar flares cause additional ionization in the ionosphere (from the highest ionospheric region $\mathrm{F}$ to the lowest ionospheric region $\mathrm{D}$ ), which consequently affected coordinate estimation and produced higher deviations, especially in the Up component with respect to EPN weekly solutions (cm-level for static and dm-level for kinematic PPP). It can be seen that higher-order ionospheric effects still remain after applying the L3 ionosphere-free solution, and this is visible in the period after 22nd October, when the solar activity was enhanced. Consequently, ionosphere was more ionized and, therefore, caused a signal delay of noticeable order that was later mapped into the PPP solution. Higher deviations of coordinate solutions can be attributed to highorder ionospheric terms, which remained after performing an ionosphere-free solution for Precise Point Positioning purposes, which is particularly visible during periods of increased solar activity. Therefore, in order to eliminate this effect, high-order ionospheric corrections should be applied in precise positioning solutions during high ionization in the ionosphere due to strong solar activity.

Acknowledgements First author is sincerely grateful to Austrian Agency for International Cooperation in Education and Research (OeAD-GmbH) for the Ernst Mach Grant Worldwide for research stay at TU Wien. Many thanks to International Center of Theoretical Physics Abdus Salam in Trieste and dr. Luigi Ciraolo for the TEC calibration program. Thanks to the following institutions, which kindly provided their data and solutions online: German Research Centre for Geosciences; NASA Omni Web of Goddard Space Flight Center; World Data Center for Geomagnetism at Kyoto University; EUREF Permanent Network (EPN) and their analysis centers; University in Stanford; Centre for Orbit Determination in Europe (CODE) and Astronomical Institute of University of Bern (AIUB). 
Funding Reference number ICM-2017-06548, financed by Bundesministerium für Wissenschaft, Forschung und Wirtschaft (BMWFW), awarding organisation: Austrian Agency for International Cooperation in Education and Research (OeAD-GmbH) and Centre for International Cooperation \& Mobility (ICM).

\section{Compliance with ethical standards}

Conflict of interest Author Randa Natras graduated (Master degree) at University of Sarajevo, Department of Geodesy, Bosnia and Herzegovina. This research was conducted during her 9-month research stay at Vienna University of Technology, Department of Geodesy and Geoinformation, Austria, which was supported by Ernst Mach Grant Worldwide.

\section{References}

1. Lang KR (2013) The life and death of stars. Cambridge University Press, Cambridge. ISBN 978-1107-01638-5

2. Schrijver CJ, Siscoe GL (eds) (2010) Heliophysics: space storms and radiation: causes and effects. Cambridge University Press, Cambridge, p 375. ISBN 1107049040

3. National Space Weather Strategy (2015) Product of National Science and Technology Council, Space weather operations, research and mitigation (SWORM) task force, USA, Oct 2015

4. Wolf $R$ (1851) Universal sunspot numbers: sunspot observations in the second part of the year 1850. Mitteilungen der Naturforschenden Gesellschaft in Bern 1:89-95

5. Covington AE (1969) Solar radio emission at $10.7 \mathrm{~cm}, 1947-$ 1968. J. R. Astron Soc Can 63:125-132

6. Rathore BS, Gupta DC, Parashar KK (2014) Relation between solar wind parameter and geomagnetic storm condition during cycle-23. Int J Geosci 5:1602-1608. https://doi.org/10.4236/ ijg.2014.513131

7. Chapman S, Bartels J (1940) Geomagnetism, Chap. 9, vol 1. Clarendon, Oxford

8. Sugiura M, Chapman S (1960) The average morphology of geomagnetic storm with sudden commencement. University of Alaska, Geophysical Institute, $53 \mathrm{pp}$

9. Richmond $A D$ (2007) lonosphere. In: Gubbins D, Herrera-Bervera $E$ (eds) Encyclopedia of geomagnetism and paleomagnetism. Springer, Heidelberg, pp 452-453

10. Hofmann-Wellenhof B, Lichtenegger H, Collins J (2001) Global positioning system: theory and practice. Springer, New York. ISBN 3-211-83534-2

11. Schaer $S$ (1999) Mapping and predicting the Earth's ionosphere using the Global Positioning System, PhD thesis, Bern University, Switzerland

12. Horozovic Dz (2014) Investigation of ionosphere and space weather and their application in positioning and navigation, MA thesis, Faculty of Civil Engineering, University of Sarajevo, Bosnia and Herzegovina

13. Natras R (2016) Research of ionosphere with geodetic methods and estimation of TEC from GNSS observations, MA thesis, Faculty of Civil Engineering, University of Sarajevo, Bosnia and Herzegovina

14. Natras R (2017) Impact of solar maximum and descending phase of solar cycle 24 on mid-latitude ionosphere, case study: Bosnia and Herzegovina. In Paper book: 10th international scientific conference students encountering sciences-StES, University of Banja Luka, Bosnia and Herzegovina, COBISS.SR-ID 5712152, ISBN 978-99976-662-9-1, pp 170-179
15. Mulic M, Natras R (2018) lonosphere TEC variations over Bosnia and Herzegovina using GNSS data. In: Cefalo R, Zieliński J, Barbarella M (eds) New advanced GNSS and 3D spatial techniques. Lecture notes in geoinformation and cartography. Springer, Cham, pp 271-283. https://doi.org/10.1007/978-3-319-56218 $-6 \_22$

16. Mulic M, Natras R, Horozovic DZ, Krdzalic DZ (2017) Investigation of ionospheric variations and sudden disturbances as a source of GNSS errors and earthquake precursor. Sci J Civ Eng SJCE Fac Civ Eng Skopje 6(2):61-68. ISSN 1857-839X

17. Horozovic DZ, Natras R, Mulic M (2018) Impact of geomagnetic storms and ionospheric disturbances on mid-latitude station's coordinates using static and kinematic PPP. Poster: European Geosciences Union, General Assembly 2018 (EGU 2018), Vienna. In: EGU General Assembly 2018. Geophysical Research Abstracts 20. ISSN: 1029-7006; 9009, 08 April 2018-13 April 2018

18. Natras R, Magnet N, Boisits J, Weber R (2018) GNSS-based regional ionosphere modeling over Bosnia and Herzegovina, poster: European Geosciences Union, General Assembly 2018 (EGU 2018), Vienna. In: “EGU General Assembly 2018", Geophysical Research Abstracts 20: 661. ISSN: 1029-7006, 08 April 2018-13 April 2018

19. https://omniweb.gsfc.nasa.gov/. Accessed 20 March 2018

20. http://swdcwww.kugi.kyoto-u.ac.jp/dstae/index.html. Accessed 20 March 2018

21. ftp://gfz-potsdam.de/pub/home/obs/kp-ap/wdc/. Accessed 23 March 2018

22. ftp://swpc.noaa.gov/pub/warehouse/. Accessed 25 March 2018

23. ftp://igs.bkg.bund.de/EUREF/. Accessed 18 March 2018

24. Scherrer D, Mitchel R, Huynh T, Lord W, Lord M (2015) SuperSID manual: space weather monitors. Stanford University, Stanford

25. https://sidstation.loudet.org/stations-list-en.xhtml/. Accessed 10 May 2018

26. http://sid.stanford.edu/database-browser/. Accessed 22 April 2018

27. ftp://swpc.noaa.gov/pub/warehouse/2014/2014_plots/xray/. Accessed 20 April 2018

28. ftp://swpc.noaa.gov/pub/warehouse/2014. Accessed 20 April 2018

29. Ciraolo L, Azpilicueta F, Brunini C, Meza A, Radicella SM (2007) Calibration error on experimental slant total electron contents (TEC) determined with GPS. J Geod 81(2):111-120

30. Dach R, Lutz S, Walser P, Fridez P (eds) (2015) Bernese GNSS software version 5.2. User manual. Astronomical Institute, University of Bern, Bern Open Publishing. https://doi.org/10.7892/boris .72297; ISBN: 978-3-906813-05-9

31. ftp://epncb.eu/pub/product/combin/. Accessed 02. May 2018

32. https://gssc.esa.int/navipedia/index.php/Transformations between_ECEF_and_ENU_coordinates. Accessed 23 Sept 2018

33. ftp://swpc.noaa.gov/pub/warehouse/2014/2014_events.tar.gz. Accessed 20 April 2018

34. Kiess C, Rezaei R, Schmidt W (2014) Properties of sunspot umbrae observed in cycle 24. Astron Astrophys 565:52. https:// doi.org/10.1051/0004-6361/201321119

35. Zharkov S, Zharkova VV, Ipson SS (2005) Statistical properties of sunspots in 1996-2004: I. Detection, north south asymmetry and area distribution. Sol Phys 228:377-397. https://doi. org/10.1007/s11207-005-5005-7

36. STCE Newsletter (2014) Published by the solar-terrestrial centre of excellence (STCE). Belgium, issue 24 Oct 2014. http://www. stce.be/newsletter/

37. https://sohowww.nascom.nasa.gov/data/synoptic/sunspots earth/sunspots_512_20141026.jpg. Accessed 13 Nov 2018 